УДК: $378.796(045)$

DOI:

Віталій Юденок, аспірант кафедри соиіальної роботи Національного університету “Чернігівський колегіум” імені Т.Г. Шевченка

\title{
ІНДИВІДУАЛЬНІ ОЗДОРОВЧО-ТРЕНУВАЛЬНІ ЗАНЯТТЯ ДЛЯ ПОКРАЩЕННЯ ФІЗИЧНОГО СТАНУ УЧНІВ СЕРЕДНЬОГО ШКІЛЬНОГО ВІКУ НА УРОКАХ ФІЗИЧНОї КУЛЬТУРИ
}

У статті розглянуто методичні особливості індивідуального підходу у процесі навчання учнів основним технічним діям у волейболі, зокрема передачі м'яча двома руками зверху на уроках фізичної культури. Встановлено, щуо методика індивідуальних занять є більш ефективною порівняно з традиційною методикою навчання технічним елементам у волейболі. Обгрунтовано особливості застосування самостійних індивідуальних оздоровчо-тренувальних занять з метою оптимізації фізичного стану учнів середнього икільного віку.

Ключові слова: учні середнього шкільного віку; самостійність; індивідуальність; здоров'я; індивідуальний метод; технічні дї; волейбол.

Лim. 13.

Vitaliy Yudenok, Postgraduate Student of the Social Work Department Taras Shevchenko National University "Chernihiv Collehium"

\section{INDIVIDUALHEALTHAND TRAINING CLASSES FOR IMPROVINGTHE PHYSICALSTATE OFTHE MIDDLE SCHOOLSTUDENTS DURING THE PHYSICALEDUCATION LESSONS}

In the article the methodical peculiarities of an individual approach in the process of teaching students to the main technical actions in volleyball are considered, in particular the transfer of the ball with two hands during the lessons of physical culture. It is established that the method of individual lessons is more effective compared to the traditional method of training for technical elements in volleyball. The peculiarities of the use of independent individual recreational and training sessions are grounded in order to optimize the physical condition of pupils of secondary school age.

In order to organize an independent physical education activities for pupils in physical education classes, it is necessary to provide homework, which they must perform daily in the form of morning hygienic gymnastics and individual health training sessions.

It is proved that in the process of conscious self-education of physical culture and recreation activity of pupils, young people create favorable conditions for improvement of indicators of health, motor readiness, increase of physical and mental efficiency, providing of motor activity, as well as development of the person as a whole.

The analysis of scientific and methodological literature has shown that the teaching of motor skills and skills at different stages of study is a complex and long-term process. From the level of development of physical qualities and abilities specific to playing volleyball, the level of possession of technical and tactical skills depends.

During the experiment and in the process of analysis of the results, it was found that the proposed method (individual lessons) is more effective than the usual basic training and should devote more time to this issue in the process of training.

Prospects for further research provide for the definition of the content of independent exercises by physical exercises of pupils of secondary school age, which needs to be selected individually, taking into account the functional capabilities and disadvantages of motor skills of students and the effectiveness of the use of an individual method of teaching with children of secondary school age in physical education classes.

Necessary task of school education is the formation of active life stance in students, which is reflected in their motivation for self-education, self-development, self-improvement.

Keywords: students of middle school age; autonomy; individuality; health; individual method; technical actions; a volleyball.

П остановка проблеми. Останніми роками спостерігається стійка тенденція загального погіршення фізичного стану учнівської молоді. Особливу увагу привертає до себе категорія учнів середнього шкільного віку, оскільки питання оптимізації фізичного та психічно-емоційного стану учнів середньої школи в умовах високого освітнього навантаження залишається відкритим.

Уроки фізичної культури не здатні повною мірою забезпечити достатній рівень рухової активності учнів, сприяти зміцненню їхнього 


\section{ІНДИВІДУАЛЬНІ ОЗДОРОВЧО-ТРЕНУВАЛЬНІ ЗАНЯТТЯ ДЛЯ ПОКРАЩЕННЯ ФІЗИЧНОГО СТАНУ УЧНІВ СЕРЕДНЬОГО ШКІЛЬНОГО ВІКУ НА УРОКАХ ФІЗИЧНОЇ КУЛЬТУРИ}

здоров’я та повноцінній фізичній підготовці, що підвищує значення самостійних занять. Тому впровадження засобів фізичної культури в умовах самостійних занять школярів є одним 3 шляхів підвищення ефективності фізичного виховання та створює додаткові можливості підвищення фізичного стану учнівської молоді (В.В. Захожий $[8,14])$.

Необхідним завданням шкільної освіти $\epsilon$ формування в учнів активної життєвої позиції, що позначається їхньою мотивацією до самонавчання, саморозвитку, самовдосконалення. Сьогодні значній частині сучасної молоді притаманний споживацький або інертний тип діяльності та поведінки у освітньому процесі, що, зокрема, проявляється у ставленні до фізичної культури як навчального предмету. Це відбивається на фізичному стані учнів середньої школи, їхніх ціннісних орієнтаціях, турботі про власне фізичне та психічне благополуччя.

Доведено, що у процесі свідомої самостійної фізкультурно-оздоровчої діяльності учнівської молоді створюються сприятливі умови для покращення показників здоров'я, рухової підготовленості, підвищення фізичної та розумової працездатності, забезпечення рухової активності, а такожрозвитку особистості в цілому(І.Б. Верблюдов, Т.О. Лоза [4, 112]).

Зважаючи на це, існує необхідність у розробці та теоретичному обгрунтуванні змісту самостійних індивідуальних оздоровчотренувальних занять для оптимізації показників фізичного стану учнів.

Процес володіння руховою діяльністю починається із формування вміння. Визначити поняття “рухове вміння” можна як сформовану на основі знань і досвіду функціональну властивість людини не автоматизовано управляти рухами в процесі моторної діяльності $[3,105 ; 10,46]$.

Техніка передачі м'яча двома руками зверху складається 3 вихідного положення і трьох послідовних фаз - зустрічного руху рук до м'яча, фази амортизації і вильоту м'яча 3 супроводжуючим рухом рук $[1,8 ; 11,195]$.

Індивідуальний підхід у процесі навчання створює найсприятливіші можливості для розвитку пізнавальних сил, активності, схильностей і обдарувань кожного учня. Сутність принципу індивідуального підходу в навчанні полягає у вивченні і врахуванні в освітньому процесі індивідуальних і вікових особливостей кожного учня 3 метою максимального розвитку позитивних і подолання негативних індивідуальних особливостей, забезпеченні на цій основі підвищення якості його навчальної роботи, всебічного розвитку $[3,106 ; 6,54]$.
Аналіз наукових досліджень. На основі аналізу наукових джерел (Г.Л. Апанасенко [2], А.В. Домашенко [5], О.М. Зварищук [9], М.О. Носко [12] Т.М. Редько [13] та ін.) встановлено, що на сучасному етапі розвитку суспільства спостерігається загальне погіршення показників фізичного стану учнівської молоді. Сьогодні визначено низький рівень функціональних можливостей та рухової підготовленості школярів. Анатомо-фізіологічні особливості розвитку організму учнів середнього шкільного віку зумовлюють необхідність особливих підходів у диференціації та дозуванні фізичних навантажень у процесі занять фізичними вправами $[7,94]$.

Мета статті. Визначення доцільності використання запропонованої методики для навчання передачі м'яча двома руками зверху та теоретичне обгрунтування особливостей застосування індивідуальних оздоровчотренувальних занять для самостійного використання учнями середнього шкільного віку 3 метою покращення фізичного стану.

Виклад основного матеріалу. Для реалізації основних завдань дослідження на різних його етапах використано такі методи: теоретичний аналіз й узагальнення науково-методичної літератури; метод педагогічного спостереження; методи визначення рівня технічної підготовленості; методи математичної статистики [6, 29].

Дослідження проводилися на базі Глухівської загальноосвітньої школи I - III ступенів в процесі занять $з$ волейболу на уроках фізичної культури. В експериментальних дослідженнях взяли участь 8 учнів $7-8$ класів.

Додаткові можливості для оптимізації фізичного стану учнів загальноосвітньої школи створюють самостійні оздоровчо-тренувальні заняття. Проте самостійна оздоровчо-фізкультурна діяльність ефективна тільки за умови адекватного змісту та дозування фізичних навантажень. Тому важливими $є$ розробка та обгрунтування раціонального змісту самостійних індивідуальних оздоровчо-тренувальних занять для учнів середнього шкільного віку з метою оптимізації їхнього фізичного стану [7, 95].

Для реалізації завдань дослідження розроблено зміст занять фізичними вправами з учнями середнього шкільного віку для щоденного самостійного виконання у формі ранкової гігієнічної гімнастики та індивідуальних оздоровчо-тренувальних занять [7, 95].

Самостійні заняття фізичними вправами 3 учнями передбачені у вигляді домашніх завдань. Через них поступово повинна формуватися звичка до самостійної фізкультурно-оздоровчої 


\section{ІНДИВІДУАЛЬНІ ОЗДОРОВЧО-ТРЕНУВАЛЬНІ ЗАНЯТТЯ ДЛЯ ПОКРАЩЕННЯ ФІЗИЧНОГО СТАНУ УЧНІВ СЕРЕДНЬОГО ШКІЛЬНОГО ВІКУ НА УРОКАХ ФІЗИЧНОӤ КУЛЬТУРИ}

діяльності, систематичне виконання якої виховує потребу у фізичному самовдосконаленні. Зміст самостійних занять фізичними вправами для учнів підбирався індивідуально, враховуючи функціональні можливості та недоліки рухової підготовленості школярів [12, 145].

Завдання для самостійної роботи тісно пов'язані з матеріалом шкільної програми, враховують сенситивні періоди розвитку рухових якостей та спрямовані на оптимізацію фізичного стану учнів [7, 96; 13, 292].

Зарубіжні науковці Н.О. Акимова $[1,12]$, Г.Л. Апанасенко [2, 45], Ю.Д. Железняк, В.А. Кунянський $[6,76]$ встановили, що на сучасному етапі розвитку суспільства спостерігається загальне погіршення показників фізичного стану учнівської молоді. Вітчизняні дослідники розвитку рухових якостей, як школярів, так й студентів А.В. Домашенко [5,11], О.М. Зварищук [9, 36], М.О. Носко [12, 145], Т.М. Редько [13, 294] та ін. виявили функціональні можливості та недоліки рухової підготовленості, як школярів, так й студентів щодо ефективності застосування індивідуального методу навчання 3 дітьми середнього шкільного віку на уроках фізичної культури. Також, важливим є дослідження таких вітчизняних науковців як І.Б. Верблюдов, Т.О. Лоза, С.В. Чередніченко, які зазначали, що організація і методика оздоровчої фізичної культури є важливою складовою рухової підготовленості школярів середнього шкільного віку $[4,196]$. Український науковець В.В. Захожий доводить, що методика формування готовності старшокласників до самостійних занять фізичними вправами має в основі підготовленість учнів середнього шкільного віку до самостійних оздоровчо-тренувальних занять $[8,16]$.

Російські дослідники Ю.М.Клещев, В.Д. Ковальов, В.О. Голомазов, С.О. Кераминас констатують, що рівень оволодіння технікою передачі м'яча двома руками зверху у волейболі має важливе значення як для занять фізичними вправами учнів середнього шкільного віку, так й для самостійних оздоровчо-тренувальних занять [10, 34; 11, 206].

Дослідження полягало в проведенні контрольних випробувань 3 визначення рівня технічної підготовленості школярів-волейболістів, які займалися індивідуально та в парах.

Для контролю рівня оволодіння технікою передачі м'яча двома руками зверху були представлені такі контрольні вправи: передачі м'яча двома руками зверху в ціль (кількість попадань) і на техніку виконання (кількість виконаних передач).

Розроблена індивідуальна методика навчання виявила достовірні зміни експериментальних досліджень $(\mathrm{P}<0,001)$.

Висновки. 3 метою організації самостійної фізкультурно-оздоровчої діяльності учнів у позанавчальний час на уроках фізичної культури необхідно надавати домашні завдання, які вони повинні виконувати щодня у вигляді ранкової гігієнічної гімнастики та індивідуальних оздоровчо-тренувальних занять.

Аналіз науково-методичної літератури показав, що методика навчання руховим умінням і навичкам на різних етапах навчання є складним та довгостроковим процесом. Від рівня розвитку фізичних якостей і здібностей, специфічних для гри у волейбол, залежить рівень володіння технікотактичними навичками.

У ході проведення експерименту та у процесі аналізу отриманих результатів було встановлено, що запропонована методика (індивідуальні заняття) ефективніша, ніж звичайна базова підготовка і слід приділяти даному питанню більше часу у процесі тренувань.

Перспективи подальших досліджень передбачають визначення змісту самостійних занять фізичними вправами учнями середнього шкільного віку, який потрібно підбирати індивідуально, враховуючи функціональні можливості та недоліки рухової підготовленості школярів та ефективності застосування індивідуального методу навчання для дітей середнього шкільного віку на уроках фізичної культури з волейболу.

\section{ЛІТЕРАТУРА}

1. Акимова Н. О., Козлова Т. Н. Индивидуальность учащегося и индивидуальный подход. Знание. 1992. № $3.24 \mathrm{c}$.

2. Апанасенко Г. Л., Попова Л. А. Медицинская валеология. Ростов-на-Дону, 2000. 248 с. (Серия "Гиппократ").

3. Білий Є. Г. Індивідуальний підхід навчання учнів середнього шкільного віку передачі м'яча двома руками зверху на уроках фізичної культури 3 волейболу. Педагогічні технологіï формування культури здоров'я особистості : Матеріали IV Всеукраїнської науковопрактичної конферениї молодих вчених $i$ студентів (5 травня 2017 року, м. Чернігів). Чернігівський національний педагогічний університет імені Т.Г. Шевченка. Відп. ред. Г. І. Жара. Чернігів: ЧНПУ імені Т.Г. Шевченка, 2017. C. 105-108.

4. Верблюдов І. Б., Лоза Т. О., Чередніченко С. В. Організація і методика оздоровчої фізичної культури: навчальний посібник для студентів 


\section{ІНДИВІДУАЛЬНІ ОЗДОРОВЧО-ТРЕНУВАЛЬНІ ЗАНЯТТЯ ДЛЯ ПОКРАЩЕННЯ ФІЗИЧНОГО СТАНУ УЧНІВ СЕРЕДНЬОГО ШКІЛЬНОГО ВІКУ НА УРОКАХ ФІЗИЧНОЇ КУЛЬТУРИ}

вищих педагогічних навчальних закладів фізичної культури. Суми: Видавництво СумдПУ ім. А. С. Макаренка, 2011. 244 с.

5. Домашенко А. В. Физическая подготовленность и здоровье населения - приоритетная задача государственного строительства. Фізична підготовленість та здоров'я населення. Одеса, 1998. C. 10-12.

6. Железняк Ю. Д., Кунянский В. А., Чачин А. В. Волейбол: методическое пособие по обучению игре. Москва, 2005. 112 с.

7. Жлобо В. О., Редько Т. М. Особливості застосування самостійних індивідуальних оздоровчо-тренувальних занять для покращення фізичного стану старшокласників. Педагогічні технології формування культури здоров'я особистості : Матеріали IV Всеукраӥнської науково-практичної конферениії молодих вчених і студентів (5 травня 2017 року, м. Чернігів). Чернігівський національний педагогічний університет імені Т.Г. Шевченка. Відп. ред. Г. І. Жара. Чернігів: ЧНПУ імені Т. Г. Шевченка, 2017. С. 93-96.

8. Захожий В. В. Методика формування готовності старшокласників до самостійних занять фізичними вправами : автореф. дис... канд. пед. наук : 13.00.02. Луцьк, 2011. 20 с.

9. Зварищук О. М. Виховання відповідальності старшокласників за свій фізичний стан: дис... канд. пед. наук з фіз. вих. та спорту : 24.00.02. Львів, 2002. $198 \mathrm{c}$.

10. Клещев Ю. Н. Волейбол. Школа тренера. Москва: Физкультура и спорт, 2005. 79 с.

11. Ковалёв В. Д., Голомазов В. А., Кераминас С. А. Спортивные игры. Москва, 2001. 318 с.

12. Носко М. О., Ляпин В. П., Сероштан В. М., Маслов В. М., Гришко Л. Г. Підвищення рівня рухової активності як чинник зміцнення здоров'я учнів та студентської молоді. Вісник Чернігівського державного педагогічного університету імені Т.Г. Шевченка. Випуск 69. Серія : Педагогічні науки. Фізичне виховання та спорт. Чернігів, 2009. № 69. С. 144-149.

13. Редько Т. М. Особливості використання кенгу джампінгу в освітньому процесі учнів старших класів. Науковий часопис Національного педагогічного університету імені М.П. Драгоманова. Серія 15 : Науково-педагогічні проблеми фізичної культури (фізична культура і спорт). 2016. Вип. 3(2). C. 291-295.

\section{REFERENCES}

1. Akimova, N. O. \& Kozlova, T. N. (1992). Individualnost uchashchegosya i individualnyy podkhod. [Student individuality and individual approach]. Knowledge. No. 3, p. 24. [in Ukrainian].

2. Apanasenko, G. L. \& Popova, L. A. (2000). Meditsinskaya valeologiya [Medical valeology]. Rostov-na-Donu: Feniks, p. 248. (Seriya "Gippokrat"). [in Russian].

3. Bilyj, Je. Gh. (2017). Indyvidualjnyj pidkhid navchannja uchniv serednjogho shkiljnogho viku peredachi m'jacha dvoma rukamy zverkhu na urokakh fizychnoji kuljtury z volejbolu. [Individual approach to teaching pupils of secondary school age to transfer the ball with two hands on top of the lessons of physical culture on volleyball]. Pedaghoghichni tekhnologhiji formuvannja kuljtury zdorov'ja osobystosti : Materialy IV Vseukrajinsjkoji naukovo-praktychnoji konferenciji molodykh vchenykh i studentiv (5 travnja 2017 roku, m. Chernighiv). - Pedagogical technologies of formation of the culture of personality health: Proceedings of the IV All-Ukrainian Scientific and Practical Conference of Young Scientists and Students (May 5, 2017, Chernihiv). Chernihiv National Pedagogical University named after T.G. Shevchenko. Vidp. red. Gh. I. Zhara. Chernighiv, pp. 105-108. [in Ukrainian].

4. Verbljudov, I. B.,Loza, T. O. \& Cherednichenko, S. V. (2011). Orghanizacija i metodyka ozdorovchoji fizychnoji kuljtury: navchaljnyj posibnyk dlja studentiv vyshhykh pedaghoghichnykh navchaljnykh zakladiv fizychnoji kuljtury [Organization and method of physical fitness: a manual for students of higher pedagogical educational institutions of physical culture]. Sumy, p. 244. [in Ukrainian].

5. Domashenko, A. V. (1998). Fyzycheskaja podghotovlennostj y zdorovj'e naselenyja pryorytetnaja zadacha ghosudarstvennogho stroyteljstva [Physical fitness and public health is a priority for state-building]. Physical preparedness and health of the population. Odesa, pp. 10-12. [in Ukrainian].

6. Zheleznyak, Yu. D., Kunyanskiy, V.A. \& Chachin, A. V. (2005). Voleybol : Metodicheskoe posobie po obucheniyu igre [Volleyball]. Moscov, p. 112. [in Russian].

7. Zhlobo, V. O. \& Redjko, T. M. (2017). Osoblyvosti zastosuvannja samostijnykh indyvidualjnykh ozdorovcho-trenuvaljnykh zanjatj dlja pokrashhennja fizychnogho stanu starshoklasnykiv. [Features of the use of independent individual health-training sessions for improving the physical condition of senior pupils]. Pedaghoghichni tekhnologhiji formuvannja kuljtury zdorov'ja osobystosti : Materialy IV Vseukrajinsjkoji naukovo-praktychnoji konferenciji molodykh vchenykh i studentiv (5 travnja 2017 roku, m. Chernighiv) - Pedagogical technologies of formation of the culture of personality health: Proceedings of 
the IV All-Ukrainian Scientific and Practical Conference of Young Scientists and Students (May 5, 2017, Chernihiv). Chernihiv National Pedagogical University named after T.G. Shevchenko. (Ed.). I. Zhara. Chernighiv, pp. 93-96. [in Ukrainian].

8. Zakhozhyj, V. V. (2011). Metodyka formuvannja ghotovnosti starshoklasnykiv do samostijnykh zanjatj fizychnymy vpravamy [Methodology of formation of high school students' readiness for independent exercises by physical exercises]. Extended abstract of candidate's thesis. Lucjk, p. 20. [in Ukrainian].

9. Zvaryshhuk, O. M. (2002). Vykhovannja vidpovidaljnosti starshoklasnykiv za svij fizychnyj stan [Upbringing the responsibility of senior pupils for their physical condition]. Candidate's thesis. Lviv, p. 198. [in Ukrainian].

10. Kleshchev, Yu. N. (2005). Voleybol. Shkola trenera [Volleyball. School Coach]. Moscov, p. 79. [in Russian].

11. Kovalev, V. D., Golomazov, V. A. \&
Keraminas, S. A. (2001). Sportivnye igry [Sport games]. Moscov, p. 318. [in Russian].

12. Nosko, M. O., Ljapyn, V. P., Seroshtan, V. M., Maslov, V. M. \& Ghryshko, L. Gh. (2009). Pidvyshhennja rivnja rukhovoji aktyvnosti jak chynnyk zmicnennja zdorov'ja uchniv ta studentsjkoji molodi [Increase in motor activity as a factor in health promotion of students]. Bulletin of Chernigov State Pedagogical University named after T.G. Shevchenko. Issue 69. Series: Pedagogical sciences. Physical education and sports. Chernighiv, pp. 144-149. [in Ukrainian].

13. Redjko, T. M. (2016). Osoblyvosti vykorystannja kenghu dzhampinghu v osvitnjomu procesi uchniv starshykh klasiv. [Features of using kengu jumping in the educational process of high school students]. Scientific journal of the National Pedagogical University named after M.P. Drahomanov. Series 15: Scientific and pedagogical problems of physical culture (physical culture and sports). 2016. Vol. 3(2), pp. 291-295. [in Ukrainian].

Стаття надійшла до редакції 11.07.2019

УДК 793.31.077

DOI:

Магдалина Марушка, здобувач кафедри загальної педагогіки та дошкільної освіти Дрогобищького державного педагогічного університету імені Івана Франка

\section{СТАНОВЛЕННЯ УКРАЇНСЫКИХ ХОРЕОГРАФІЧНИХ ШКІЛ У КОНТЕКСТІ РОЗВИТКУ ЄВРОПЕЙСЬКОЇ ХУДОЖНЬОЇ КУЛЬТУРИ ПОЧАТКУ ХХ СТ.}

Стаття присвячена аналізу історії формування хореографічних шкіл та студій в Украӥні на початку ХХ століття. Становлення украӥнської професійної хореографічної освіти в Украйні тісно пов'язано з розвитком класики, з формуванням західноєвропейської, а саме, французької і італійськоӥ шкіл та перших таниңювальних студій у XIX cm. У перші десятиліття XX ст. були започатковано систему навчальних хореографічних закладів. Базовим принцииом навчання у хореографічних иколах стала традиція класичного танцю, яка має продовження і сьогодні.

Ключові слова: хореографічна освіта; хореографічна школа; класична хореографія; народно-сценічна хореографія; хореографічне мистецтво.

תim. 5.

Mahdalyna Marushka, Postgraduate Student of the General and Preschool Education Department Drohobych Ivan Franco State Pedagogical University

\section{THE FORMATION OF UKRAINIAN CHOREOGRAPHIC SCHOOLS IN THE CONTEXT OFTHE DEVELOPMENT OF THE EUROPEAN ARTISTIC CULTURE OF THE EARLY TWENTIETH CENTURY}

The article is devoted to the analysis of the history of the formation of choreographic schools and studios in Ukraine at the beginning of the 20th century. The formation of Ukrainian professional choreographic education in Ukraine is closely linked to the development of classics, with the formation of Western European, namely, the French and Italian schools and the first dance studios in the nineteenth century. In the first decades of the twentieth century. the system of educational choreographic establishments was started. The basic principle of studying in choreographic schools is the tradition of classical dance, which continues today.

In conditions of economic decline, military and political struggle, there was a marked rise in cultural and scientific life, which was caused by the aspirations of the Ukrainian national revival. Only in 1918 the State Drama School was founded, the Ukrainian State Theater, solemnly opened by the Ukrainian Academy of Sciences. Ukrainian schools and gymnasia began to appear in different regions. 